\title{
Advantage of clonal deployment in Norway spruce (Picea abies (L.) H. Karst)
}

\author{
Zhi-Qiang Chen ${ }^{1} \cdot$ Hong Nguyen Thi Hai ${ }^{1,2} \cdot$ Andreas Helmersson $^{3} \cdot$ Mateusz Liziniewicz ${ }^{3} \cdot$ Henrik R. Hallingbäck ${ }^{1,4,5}$. \\ Anders Fries ${ }^{1} \cdot$ Mats Berlin $^{5} \cdot$ Harry X. Wu ${ }^{1,6,7}$
}

Received: 16 September 2019 / Accepted: 10 January 2020 / Published online: 28 January 2020

(C) The Author(s) 2020

\begin{abstract}
- Key message There is considerable genetic gain of tree volume from clonal deployment in Norway spruce (Picea abies (L.) H. Karst) and clonal deployment will have at least $50 \%$ more or double genetic gain than the seedling deployment. - Context Genetic parameters and genetic gains for wood quality and growth traits were estimated in six large clonal progeny trials.

- Aims Develop the optimal clonal deployment strategy of Norway spruce in Sweden.

- Methods Wood quality and growth traits were measured in all clonal trials and additive and non-additive genetic variances are partitioned.

- Results Additive and non-additive genetic variances were equally important for growth traits while non-additive variance was small or not significant for wood quality trait. The genetic gain predicted for clonal deployment was greater than any of the other four deployment strategies. Selecting the top $1 \%$ of tested clones (clonal forestry) would have $48.4 \%$ and $134.6 \%$ more gain than the gain predicted for the seedling deployment of selected full-sib families and half-sib family (family forestry), respectively, at the same selection intensity.

- Conclusion This study highlights that testing of 30-40 clones per family would maximize the realized genetic gain for different clonal selection scenarios, either selecting the best ten or 20 clones without any co-ancestry restrictions or selecting the best single clone from each of the best ten or 20 families (e.g., co-ancestry restriction). Clonal mean selection and vegetative deployment are the most effective.
\end{abstract}

Keywords Clonal forestry $\cdot$ Family forestry $\cdot$ Wood quality traits $\cdot \mathrm{DBH} \cdot$ Genetic gain $\cdot$ Non-additive genetic variance

Handling Editor: Ricardo Alia

Contribution of the co-authors $\mathrm{HXW}, \mathrm{MB}, \mathrm{ZQC}, \mathrm{AH}$, and $\mathrm{ML}$ initiated the project. ZQC, AF, HNTH, AH, ML, and HRH conducted the data collection. ZQC conducted the data analysis and wrote the manuscript. HXW, HRH, AF, MB, ML, AH, and HNTH contributed to the writing of the manuscript. All the authors read and approved the final manuscript.

Harry X. Wu

Harry.wu@slu.se

Zhi-Qiang Chen

zhiqiang.chen@slu.se

Hong Nguyen Thi Hai

hong.nguyen@vafs.gov.vn

Andreas Helmersson

Andreas.Helmersson@skogforsk.se

Mateusz Liziniewicz

mateusz.liziniewicz@skogforsk.se
Henrik R. Hallingbäck

henrik.hallingback@slu.se

Anders Fries

Anders.Fries@slu.se

Mats Berlin

Mats.Berlin@skogforsk.se

Extended author information available on the last page of the article 


\section{Introduction}

The total genetic variance in a biological trait can be partitioned into additive, dominance, and epistatic variances (Falconer and Mackay 1996). In forestry, however, quantitative geneticists have commonly ignored the interaction between alleles (dominance) at a locus and the interactions alleles between loci (epistasis) in the analysis of progeny trials (Foster and Shaw 1988). The main reasons are the lack of well-designed experiments with a full-sib family structure in a clonally replicated trial and limited number of families and clones within a family tested. Traditionally, two methods have been used to partition the genetic variance in forestry without using inbreeding methods. First, Foster and Shaw (1988) estimated the epistatic genetic variance from a clonally replicated experiment using the expected covariance among relatives. The model assumes that the epistatic genetic effect is mainly from numerous high-order interactions between loci. In contrast, another model proposed by $\mathrm{Wu}$ (1996) was based on the assumption that epistasis for a quantitative trait is limited to interactions between pairs of quantitative trait loci (QTL) only. Currently, many tree species based on genomic data has discovered significant epistatic genetic variance based on the interaction between QTL pairs, such as additive $\times$ additive, additive $\times$ dominance, and dominance $\times$ dominance interaction effects (Muñoz et al. 2014; Bouvet et al. 2016; Gamal ElDien et al. 2016; Chen et al. 2019; Tan et al. 2018). Without clonally replicated experiments, however, it is difficult to explain how total genetic variance is distributed among the three components and make a sound judgment in optimal deployment strategy.

Mullin and Park (1992) defined five types of commonly used heritabilities applicable to full-sib clonal trials and its relevance for selection and deployment strategies in forestry. They are as follows: (1) narrow-sense heritability $\left(h^{2}\right)$; (2) broadsense heritability $\left(H^{2}\right)$; (3) half-sib family mean heritability $\left(H_{\overline{\mathrm{HS}}}^{2}\right)$; (4) full-sib family mean heritability $\left(H_{\overline{\mathrm{FS}}}^{2}\right)$; and (5) clone mean heritability $\left(H_{\overline{\mathrm{CL}}}^{2}\right)$. For each of the five types of heritability, a corresponding selection and deployment strategy was proposed as: (1) forward mass selection of the best individuals and selected trees grafted into seed orchards for deployment of their seedlings (i.e., Seedling-based Open-Pollinated individual Forward selection (SOPF)); 2) forward mass selection of the best individuals and deployment with vegetative propagation (i.e., Clonal-based INdividual Forward selection (CINF)) using rooted cuttings (RC) or somatic embryogenesis (SE); (3) selecting the best parents based on their breeding values (backward general combining ability (GCA) selection) followed by repeated crossings in nature or in a grafted seed orchard in order to produce and deploy the progeny seedlings (i.e., Seedling-based Half-Sib family Backward selection (SHSB)); (4) selecting the best full-sib family (backward specific combining ability (SCA) selection) followed by repeated controlled crosses in a grafted seed orchard in order to produce and deploy progeny seedlings (i.e., Seedling-based FullSib family Backward selection (SFSB)); and 5) selecting the best clones, tested in a trial with replication, followed by deployment of these clones using vegetative propagation methods such as RC or SE (i.e., Clonal-based Replicated Clone Forward selection (CRCF)). In summary, $h^{2}, H^{2}$, and $H_{\overline{\mathrm{CL}}}^{2}$ were used to forward mass selection, while $H_{\overline{\mathrm{HS}}}^{2}$ and $H_{\overline{\mathrm{FS}}}^{2}$ are used to backward mass selection. The three selection and deployment strategies including SOPF, SHSB, and SFSB which are related to $h^{2}, H_{\overline{\mathrm{HS}}}^{2}$, and $H_{\overline{\mathrm{FS}}}^{2}$, respectively, are often referred to as family forestry strategies and are based on all seedlings produced or rooted cuttings from these seedlings in some conifer species such as radiata pine in Australia and Norway spruce in Sweden. CINF and CRCF are, on the other hand, referred to as clonal forestry because the best clones were selected for vegetative propagation and deployment. The only difference between $\mathrm{CRCF}$ and CINF is that the latter does not require the establishment of a clonally replicated test but rather deploy the best individuals using vegetative propagation.

Norway spruce (Picea abies (L.) H. Karst) is the most commercially important tree species in Swedish forestry (Hannrup et al. 2004). The Swedish breeding program for Norway spruce has been focused on growth, survival, branch quality, and wood density (Rosvall et al. 2011). Genetic parameters have been estimated for many full-sib and half-sib seedling progeny trials (Hannrup et al. 2004; Kroon et al. 2011; Chen et al. 2014) and also for clonal trials, but without family structure (Bentzer et al. 1989; Karlsson et al. 2001; Högberg and Dutkowski 2010; Isik et al. 2010). A most recent study of Norway spruce in clonal trials included family structure (Berlin et al. 2019), but considered just growth properties. There was a particular call to accurately estimate non-additive genetic variance for Norway spruce in a recent review of clonal forestry of Norway spruce (Wu 2018). In estimating genetic parameters using clone trials in conifer, another issue is that the number of families available has usually been in the low double-digit figures (Baltunis et al. 2007; Weng et al. 2008) or even less than ten (Isik et al. 2003; Isik and Kleinschmit 2005). The limited population size makes it difficult to accurately estimate the different sources of the genetic variance of growth traits. For the purpose of clonal forestry deployment, selection mainly focuses on the genetic variation within just a few elite families. Thus, it is important to capture enough of the variation (number clones per family) within these elite families. Therefore, one issue is to find the optimal number of clones per family in order to capture a large part of the within-family variation, achieve largest genetic gains, and maintain genetic diversity under constraints of the trial size and costs. This issue has not yet been sufficiently resolved for Norway spruce. 
The aims of this study were to (1) partition the total genetic variance into additive and different non-additive sources of variation for growth and wood quality traits assessed at different ages in clonally replicated field trials of large family size; (2) estimate genetic parameters for growth and wood quality traits and compare them with previous studies in Norway spruce; and (3) evaluate the effects of family size and diversity on the genetic gain in a population. This study was done in four control-pollinated and two open-pollinated clonal trials of Norway spruce located in southern and central Sweden.

\section{Materials and methods}

\subsection{Plant material and field trial}

\subsubsection{Full-sib clonal trials}

The seed underlying the clonal material of this study originated from a sparse partial diallel mating design between selected and trees within southern Sweden's seed orchard zone 8-9S. Forty-nine parents including 30 females and 22 males were used for making the crosses. In total, 32 full-sib crosses have been done. The produced seeds were sown in spring 2001 into pots. After 1-year growth, the seedling (donor) plants were transplanted to nursery beds and arranged in a row-wise manner with an average of approximately 60 donor plants per family (range from 11 to 109 surviving plants per family). In the early spring of 2004, clones for the propagation of cuttings were visually selected within each family based on good growth and vitality. Roughly $70 \%$ of the donor plants per family were selected as candidates for field testing (varying between 38 and $97 \%$ of clones within each family).

Finally, rooted cuttings from 1430 clones from 32 full-sib families were planted in four clonal trials in 2007, which were registered as S21S0721387 (S1387), S21S0721388 (S1388), S21S0721389 (S1389), and S21S0721390 (S1390). A randomized incomplete block design using the single-tree plot was used in all four trials. Finally, each family from four trials had an average of 44.7 clones (18-64 clones). Detailed descriptions about location, soil type, and climate condition of trials are given in Table 1.

\subsubsection{Half-sib clonal trials}

Two clonal half-sib progeny trials of Norway spruce, S22S94202237 (S237) at Lugnet and S22S94202239 (S239) at Grangärde, were established in 1994 in central Sweden. The detailed description of the two trials was shown in Table 1. Rooted cuttings for 2244 clones from 138 half-sib families were planted with an average of 16.9 clones for each family. A randomized incomplete block design using a single-tree plot was used in both trials.

\subsection{Measurement of Pilodyn penetration depth in standing trees}

In order to indirectly assess wood density under the bark, the Pilodyn penetration depth (Pilo) was measured using a Pilodyn 6J Forest (PROCEQ, Zurich, Switzerland) with a 2.0-mm diameter pin, without removing the bark. The measurement was conducted at approximately $1.3 \mathrm{~m}$ above the ground for each tree and on the same side for all trees in the trial S239 (Table 2). In the trial S1387, Pilo was measured from two sides of the tree and the average was used for the analysis.

\subsection{Measurement of the resistograph}

The micro-drill Resistograph IML-RESI PD300 (Instrumenta Mechanic Labor, Germany) was used, as an alternative method in order to determine the wood density of standing trees in the trial S237. The resistograph was used for drilling trees bark to pith to bark at a tree height of ca. $1.3 \mathrm{~m}$ and special attention was paid to avoiding drilling through knots or visible stem damages. Each profile was checked immediately after drilling on the tool's screen and the measurement was repeated when necessary. Custom software is available from a web URL (https://forestquality.shinyapps.io/EucalyptResiProcessor/) (Downes et al. 2018). Finally, the mean resistance (resistograph (Resi)) values were provided from the data profile.

\subsection{Measurement of acoustic velocity}

The Hitman ST300 tool (Fiber-gen, Christchurch; New Zealand) was used to determine the acoustic velocity (AV) at the tree side with fewer branches in two half-sib trials (Table 2). All obstructing branches below the height of approximate $2 \mathrm{~m}$ were removed from the trees before the measurement. To avoid knots as much as possible, the upper probe was usually inserted just below the higher branch whorl and the lower probe was placed just above the lower whorl.

\subsection{Estimating the dynamic modulus of elasticity}

Based on the observed high correlations between Pilo and wood density, between AV and microfibril angle (MFA) (Chen et al. 2015), and between resistograph (Resi) and wood density (Fundova et al. 2018), either Pilo or Resi was used as a surrogate for estimation of wood density of a standing tree. The dynamic modulus of elasticity (MOE) was thus calculated using the following two models, respectively:

$\mathrm{MOE}=\frac{10,000}{\text { Pilo }} \times \mathrm{AV}^{2}$ or MOE $=\frac{1}{3} \times \operatorname{Resi} \times \mathrm{AV}^{2}$. 
Table 1 Details for the six clonal field trials in southern and central Sweden

\begin{tabular}{|c|c|c|c|c|c|c|}
\hline Details & S237 & S239 & S1387 & S1388 & S1389 & S1390 \\
\hline Site & Lugnet, Bålsta & Grangärde & Tagels gård & Skåne Fagerhult & Rössjöholm & Knutstorp \\
\hline Latitude (north) & 59.63 & 60.28 & 57.16 & 56.40 & 56.30 & 56.02 \\
\hline Longitude (west) & 17.31 & 15.12 & 14.40 & 13.47 & 13.13 & 13.09 \\
\hline Altitude (m) & 10 & 300 & 220 & $112 / 135$ & 105 & 115 \\
\hline Mean annual rainfall $(\mathrm{mm})$ & 593.7 & 811.0 & 832.6 & 958.3 & 1002.7 & 1044.4 \\
\hline Mean annual temperature $\left({ }^{\circ} \mathrm{C}\right)$ & 7.3 & 5.0 & 6.8 & 7.7 & 8.1 & 8.4 \\
\hline Soil type & Agricultural & Podzol & Podzol & Podzol & Podzol & Podzol \\
\hline Number of clones & 2243 & 804 & 1428 & 1424 & 1412 & 1409 \\
\hline Number of families & 148 & 118 & 32 & 32 & 32 & 32 \\
\hline Number of ramets/clone & 4.1 & 5.0 & 3.6 & 3.5 & 3.4 & 3.2 \\
\hline Type of material & Half-sib & Half-sib & Full-sib & Full-sib & Full-sib & Full-sib \\
\hline
\end{tabular}

\subsection{Measurement of growth traits}

The tree height $(\mathrm{cm})$ was measured by the tangent (clinometer) method and the diameter at breast height, ca. $1.3 \mathrm{~m}(\mathrm{DBH}, \mathrm{mm})$, was measured by digital calipers.

\subsection{Estimating the tree volume}

Volume (VOL) of each tree $\left(\mathrm{dm}^{3}\right)$ was estimated with a function by Brandel (1990):

$$
\begin{aligned}
\mathrm{VOL}= & 10^{-1.02039} \times \mathrm{DBH}^{2.00128} \times(\mathrm{DBH}+20.0)^{-0.47473} \\
& \times \mathrm{HT}^{2.87138} \times(\mathrm{HT}-1.3)^{-1.61803}
\end{aligned}
$$

where $\mathrm{DBH}$ is the diameter at breast height $(1.3 \mathrm{~m})(\mathrm{cm})$ and HT is the tree height $(\mathrm{m})$.

\subsection{Statistical analysis}

\subsubsection{Full-sib trials}

Across-site analyses for traits measured in the four southern Swedish full-sib clonal trials were conducted with the following single-tree model

$y=\boldsymbol{X} b+\boldsymbol{Z}_{\mathbf{1}} a+\boldsymbol{Z}_{\mathbf{2}} f+\boldsymbol{Z}_{\mathbf{3}} c+\boldsymbol{Z}_{\mathbf{4}} \mathrm{al}+\boldsymbol{Z}_{\mathbf{5}} \mathrm{fl}+\boldsymbol{Z}_{\mathbf{6}} \mathrm{cl}+e$

where $y$ is the vector of the observations for a specific trait in the four full-sib clonal trials, $b$ is the vector of fixed effects (i.e., overall mean, trial, and complete blocks within a trial), $a$, $f, c, a l, \mathrm{fl}$, and $\mathrm{cl}$ are the vectors of random additive genetic effects of individual genotypes, random special combining ability (SCA) effects, clones within full-sib family effects, additive genetic effect by location (trial) interaction effects, SCA-by-location effects, and clones within full-sib familyby-location effects, respectively. $X, Z_{1}, Z_{2} Z_{3}, Z_{4}, Z_{5}$, and $Z_{6}$ are the known incidence matrices related to the $b, a, f, c$, al, $\mathrm{fl}$, and $\mathrm{cl}$, respectively. The variances associated with the random effects: $a, f, c$, al, fl, and cl, are referred to as $\mathrm{A} \hat{\sigma}_{A}^{2}, \mathrm{I} \hat{\sigma}_{\mathrm{SCA}}^{2}, \mathrm{I} \hat{\sigma}_{C}^{2}$, $\mathrm{A} \hat{\sigma}_{A x L}^{2}, \mathrm{I} \hat{\sigma}_{\mathrm{SCAxL}}^{2}$, and $\mathrm{I} \hat{\sigma}_{C x L}^{2}$, respectively, where $A$ is the pedigree relationship and $I$ is the incidence matrix. The vector $e$ represents residual effects $\sim N(0, R)$, with heterogeneity of variance among $j$ sites $R=\sigma_{e_{1}}^{2} I_{n_{1}} \oplus \sigma_{e_{2}}^{2} I_{n_{2}} \oplus \ldots \oplus \sigma_{e_{j}}^{2} I_{n_{j}}$, where $\oplus$ is the direct sum The average of the four residual variances from the four full-sib trials $\sigma_{e}^{2}$ was also estimated. Traits of HT, VOL, and Pilo at age 12 were only measured in the S1387 full-sib trial (Table 2); thus, the following single-site and single-tree model was used:

$y=\boldsymbol{X} b+\boldsymbol{Z}_{\mathbf{1}} a+\boldsymbol{Z}_{\mathbf{2}} f+\boldsymbol{Z}_{\mathbf{3}} c+e$

where all effects are the same as Eq. (1), except that $b$ only includes the overall mean and block effects.

\subsubsection{Half-sib trials}

The across-site analysis for all traits in the two half-sib trials used the following single-tree model

Table 2 The traits measured/predicted and ages in the six clonal field trials in southern and central Sweden

\begin{tabular}{llllccc}
\hline Traits (units) & S237 & S239 & S1387 & S1388 & S1389 & S1390 \\
\hline HT (dm) & $3,6,13$ & 3,6 & 6,12 & 6 & 6 & 6 \\
DBH (mm) & 13,25 & 14,25 & 12 & 12 & 12 & 12 \\
VOL $\left(\mathrm{dm}^{3}\right)$ & 13 & & 12 & & & \\
Pilo $(\mathrm{mm})$ & & 25 & 12 & & & \\
Resi & 25 & & & & & \\
AV (km/s) & 25 & 25 & & & & \\
MOE $(\mathrm{GPa})$ & 25 & 25 & & & & \\
\hline
\end{tabular}

$H T$ tree height; $D B H$ diameter at breast height; VOL tree volume; Pilo Pilodyn penetration depth; Resi resistograph; $A V$ acoustic velocity measured by Hitman ST 300 tool, MOE modulus of elasticity of wood 
$y=X b+Z_{0} b_{0}+Z_{1} a+Z_{3} n+Z_{4} \mathrm{al}+Z_{6} \mathrm{nl}+e$

where $y$ is the vector of the observations for trait in two halfsib clonal trials, $b$ is the vector of fixed effects (i.e., overall mean and trial), and $a$ and $a l$ are defined as above, except for $b_{0}, n$, and $\mathrm{nl}$, which are the vectors of incomplete block within a trial, clones within half-sib family (i.e., non-additive effects), and clones within half-sib family-by-location effects, respectively. $\boldsymbol{X}, \mathbf{Z}_{0}, \boldsymbol{Z}_{\mathbf{1}}, \boldsymbol{Z}_{\mathbf{3}}, \boldsymbol{Z}_{\mathbf{4}}$, and $\boldsymbol{Z}_{\mathbf{6}}$ are the known incidence matrices related to the $b, b_{0}, a, n$, al, and nl, respectively. The variances associated with the random effects: $b_{0}, a, n$, al, and nl, were referred to $\hat{\sigma}_{b}^{2}, \hat{\sigma}_{A}^{2}, \hat{\sigma}_{N}^{2}, \hat{\sigma}_{A x L}^{2}$, and $\hat{\sigma}_{N x L}^{2}$, respectively. In the half-sib trials, to avoid confounding of incomplete block and genetic effects, the block effects were here assumed to be random. The vector $e$ represents residual effects $\sim N(0, R)$, where heterogeneity of variance between the two sites is modeled as $R=\sigma_{e_{1}}^{2} I_{n_{1}} \oplus \sigma_{e_{2}}^{2} I_{n_{2}}$, and the average of the two residual variances from the two half-sib trials $\sigma_{e}^{2}$ was also estimated. All traits measured in only a single half-sib family clonal trial (see Table 2) were analyzed with the single-site and single-tree model as follows

$y=X b+Z_{0} b_{0}+Z_{1} a+Z_{3} n+e$

where all the definitions of the respective effects are the same as in Eq. (3).

The variance associated with

$\hat{V}_{\mathrm{A}}=\partial_{\mathrm{A}}^{2}=V_{\mathrm{A}}+\frac{1}{4} V_{\mathrm{AA}}+\frac{1}{16} V_{\mathrm{AAA}}$

is the estimate of additive genetic variance in both full-sib and half-sib trials. $V_{\mathrm{A}}, V_{\mathrm{AA}}$, and $V_{\mathrm{AAA}}$ pertain to the additive genetic variance and epistatic genetic variance due to interactions of additive effects at two and three loci, respectively.

$\widehat{V}_{\mathrm{D}}=4 \hat{\sigma}_{\mathrm{SCA}}^{2}=V_{\mathrm{D}}+\frac{1}{2} V_{\mathrm{AA}}+\frac{1}{2} V_{\mathrm{AD}}+\frac{1}{4} V_{\mathrm{DD}}$ is the estimate of dominance genetic variance in full-sib clonal trials. $V_{\mathrm{D}}, V_{\mathrm{AA}}, V_{\mathrm{AD}}$, and $V_{\mathrm{DD}}$ correspond to dominance genetic variance and epistatic genetic variance due to interactions of additive-by-additive, additive-by-dominance, and dominanceby dominance effects at two loci.

$\hat{V}_{\mathrm{I}}=\hat{\sigma}_{\mathrm{C}}^{2}-3 \hat{\sigma}_{\mathrm{SCA}}^{2}=\frac{1}{4} V_{\mathrm{AA}}+\frac{1}{2} V_{\mathrm{AD}}+\frac{3}{4} V_{\mathrm{DD}}$

is the estimate of epistatic genetic variance in full-sib clonal trials and

$\hat{V}_{\mathrm{N}}=\hat{\sigma}_{\mathrm{N}}^{2}$

is the non-additive genetic (dominance and epistatic) variance in the half-sib clonal trials. To estimate the total genetic variance $\left(\hat{V}_{\mathrm{G}}\right)$, the equations:

$\hat{V}_{\mathrm{G}}=\hat{\sigma}_{\mathrm{A}}^{2}+\hat{\sigma}_{\mathrm{SCA}}^{2}+\hat{\sigma}_{\mathrm{C}}^{2}$

and

$\hat{V}_{\mathrm{G}}=\hat{\sigma}_{\mathrm{A}}^{2}+\hat{\sigma}_{\mathrm{N}}^{2}$

were used to full-sib and half-sib clonal trials, respectively. Furthermore, the total phenotypic variance was estimated as

$\hat{V}_{\mathrm{P}}=\hat{\sigma}_{\mathrm{A}}^{2}+\hat{\sigma}_{\mathrm{SCA}}^{2}+\hat{\sigma}_{\mathrm{C}}^{2}+\hat{\sigma}_{A x L}^{2}+\hat{\sigma}_{\mathrm{SCA} x L}^{2}+\hat{\sigma}_{C x L}^{2}+\hat{\sigma}_{e}^{2}$

and

$\hat{V}_{\mathrm{P}}=\hat{\sigma}_{\mathrm{A}}^{2}+\hat{\sigma}_{\mathrm{N}}^{2}+\hat{\sigma}_{A x L}^{2}+\hat{\sigma}_{N x L}^{2}+\hat{\sigma}_{e}^{2}$

for full-sib and half-sib clonal trial analyses, respectively. Also, we adjusted the equation (Weng et al. 2008) to calculate the phenotypic variances of half-sib family means as

$\hat{V}_{P}=\frac{1}{4} \hat{\sigma}_{\mathrm{AS}}^{2}+\left(k_{2} \hat{\sigma}_{\mathrm{SCA}}^{2}+k_{3}\left(\hat{\sigma}_{\mathrm{C}}^{2}+\frac{1}{2} \hat{\sigma}_{\mathrm{A}}^{2}\right)+\frac{1}{4} k_{4} \hat{\sigma}_{A x L}^{2}+k_{5} \hat{\sigma}_{\mathrm{SCA} A L}^{2}+k_{6}\left(\hat{\sigma}_{C x L}^{2}+\frac{1}{2} \hat{\sigma}_{A x L}^{2}\right)+\hat{\sigma}_{e}^{2}\right) / k_{1}$

and

$\hat{V}_{P}=\frac{1}{4} \hat{\sigma}_{\mathrm{AS}}^{2}+\left(k_{8}\left(\hat{\sigma}_{\mathrm{N}}^{2}+\frac{3}{4} \hat{\sigma}_{\mathrm{A}}^{2}\right)+\frac{1}{4} k_{9} \hat{\sigma}_{A x L}^{2}+k_{10}\left(\hat{\sigma}_{N x L}^{2}+\frac{3}{4} \hat{\sigma}_{A x L}^{2}\right)+\hat{\sigma}_{e}^{2}\right) / k_{7}$

for full-sib and half-sib clonal trials, respectively. The coefficients of denominator degrees of freedom are $k_{1}-k_{6}$ and $k_{7}-$ $k_{10}$ for the model terms of full-sib and half-sib clonal trials, respectively, and were necessary for the correct calculation of family mean variances. To obtain these coefficients, additional analyses were made where the respective individual linear models (Eqs. (1-4)) were replaced with equivalent parental family models, but with homogenous residual variances for different trials. From the results of those analyses, the coefficients were extracted by using the DDF function in ASReml 4.1. The principal difference between individual and family models was that parental general combining ability (GCA) term replaced the additive genotype effect term. This implies a variance relationship between GCA variance and additive genetic variance as $\hat{\sigma}_{\mathrm{GCA}}^{2}=\frac{1}{4} \hat{\sigma}_{A}^{2}$ which was accounted for when applying the coefficients for downstream family mean 
variance calculations. In addition to $\hat{V}_{P_{\overline{\mathrm{HS}}}}$, we also adjusted the equation (Weng et al. 2008) to calculate the phenotypic variance of full-sib family means in full-sib clonal trials as:

$\hat{V}_{P \overline{\mathrm{FS}}}=\frac{1}{2} \hat{\sigma}_{A}^{2}+\hat{\sigma}_{\mathrm{SCA}}^{2}+\left(k_{3}\left(\hat{\sigma}_{C}^{2}+\frac{1}{2} \hat{\sigma}_{A}^{2}\right)+k_{5} \hat{\sigma}_{\mathrm{SCA} x L}^{2}+k_{6}\left(\hat{\sigma}_{C x L}^{2}+\frac{1}{2} \hat{\sigma}_{A x L}^{2}\right)+\hat{\sigma}_{e}^{2}\right) / k_{2}$

Finally, phenotypic variances of clonal means were calculated as:

$$
\hat{V}_{P \overline{\mathrm{CL}}}=\hat{\sigma}_{\mathrm{A}}^{2}+\hat{\sigma}_{\mathrm{SCA}}^{2}+\hat{\sigma}_{\mathrm{C}}^{2}+\left(k_{6}\left(\hat{\sigma}_{c x L}^{2}+\frac{1}{2} \hat{\sigma}_{A x L}^{2}\right)+\hat{\sigma}_{e}^{2}\right) / k_{3}
$$

and

$$
\hat{V}_{P \overline{\mathrm{CL}}}=\hat{\sigma}_{\mathrm{A}}^{2}+\hat{\sigma}_{\mathrm{N}}^{2}+\left(k_{10}\left(\hat{\sigma}_{N x L}^{2}+\frac{3}{4} \hat{\sigma}_{A x L}^{2}\right)+\hat{\sigma}_{e}^{2}\right) / k_{7}
$$

for analyses of full-sib and half-sib clonal trials, respectively. When those estimated variances are related to single-site analyses, genetic-by-location interaction effects were excluded from the four estimated phenotypic variances above.

\subsection{Heritability estimates}

With respect to heritability, $h^{2}=\hat{V}_{\mathrm{A}} / \hat{V}_{\mathrm{P}}$ is the estimate of individual-tree narrow-sense heritability; $H^{2}=\hat{V}_{\mathrm{G}} / \hat{V}_{\mathrm{P}}$ is the estimate of individual-tree broad-sense heritability; $H_{\overline{\mathrm{HS}}}^{2}=\frac{1}{4} \hat{V}_{\mathrm{A}} / \hat{V}_{P_{\overline{\mathrm{HS}}}}$ is the half-sib family mean heritability; $H_{\overline{\mathrm{FS}}}^{2}=\left(\frac{1}{2} \hat{V}_{\mathrm{A}}+\hat{\sigma}_{\mathrm{SCA}}^{2}\right) / \hat{V}_{P_{\overline{\mathrm{FS}}}}$ is the full-sib family mean heritability; and $H_{\overline{\mathrm{CL}}}^{2}=\hat{V}_{\mathrm{G}} / \hat{V}_{P_{\overline{\mathrm{CL}}}}$ is the clonal mean heritability. Approximate standard errors for variance components and heritabilities were estimated using the Taylor series expansion method in ASReml 4.1 (Gilmour et al. 2015).

\subsection{Expected genetic gain}

The expected genetic gain $(\Delta G)$ as a percentage of the overall trait mean $(\bar{y})$ was estimated for five types of selection and deployment strategies (Mullin and Park 1994) under the selection intensity of $i=2.67$ (i.e., 1\%). The selection and deployment strategies included (1) individual forward mass selection and grafted seed orchard (SOPF); (2) individual forward mass selection and cloning (CINF); (3) backward selection of parents (GCA) and polycross (SHSB); (4) backward selection of specific parent pairs and repeat crossing (SFSB); and (5) forward selection based on clonal means followed by further vegetative propagation (CRCF). Based on each selection and deployment strategy, the following formulae for each of expected genetic gain (White et al. 2007) were used:

$\Delta G_{h^{2}}=\frac{100 \hat{h}^{2} i}{\bar{y}} \sqrt{\hat{V}_{P}}$

is the genetic gain associated with SOPF;

$$
\Delta G_{H^{2}}=\frac{100 \hat{H}^{2} i}{\bar{y}} \sqrt{\hat{V}_{P}}
$$

is the genetic gain associated with CINF;

$$
\Delta G_{H^{2}}=\frac{100 \hat{H}_{\overline{H S}}^{2} i}{\bar{y}} \sqrt{\hat{V}_{P \overline{\mathrm{HS}}}}
$$

is the genetic gain associated with SHSB;

$$
\Delta G_{H^{2}}=\frac{100 \hat{H}_{\overline{\mathrm{FS}}}^{2} i}{\bar{y}} \sqrt{\hat{V}_{P}}
$$

is the genetic gain associated with SFSB;

$$
\underset{\substack{\mathrm{CL}}}{\Delta G_{H^{2}}}=\frac{100 \hat{H}_{\overline{\mathrm{CL}}}^{2}}{\bar{y}} \sqrt{\hat{V}_{\overline{\mathrm{CL}}}}
$$

is the genetic gain associated with $\mathrm{CRCF}$.

\subsection{The optimal family size for clonal testing}

In order to estimate the optimal family size (number of clones within a full-sib family) for both maximized genetic gain and then maintain recommended diversity (10-20 clones based on simulation (Ingvarsson and Dahlberg 2018)) in clonal forestry $(\mathrm{CRCF})$, random subsets of clones at the range 5, 10, 15, 20, $25,30,35$, and 40 clones without replacement from each of the 32 full-sib families present in the full-sib clonal trials were sampled to estimate the trend of the genetic gain. To account for the long-term risks associated with the deployment of a few and possibly interrelated clones in Swedish forest stands (Rosvall et al. 2019), four selection strategies were evaluated: (1) selecting the best ten clones without any restrictions on the 
relationships among the selected clones and (2) selecting the best single clone within each of the ten best families, and (3) selecting the best 20 clones without relationship restrictions and (4) selecting the best single clone within each of the 20 best families. Thus, 32 combinations of family-size and selection strategy were evaluated and the random subset sampling procedure was repeated ten times for each scenario. The genetic gain $(\%)$ was calculated as

$\Delta G=\frac{100 \sum p_{i} \mathrm{GV}_{i}}{\bar{y}}$

where $p_{i}$ is the fractional contribution to the clonal mixture by the $i$ th clone and $\mathrm{GV}_{i}$ is the $i$ th clonal genetic value ( $\mathrm{GV}=\boldsymbol{Z}_{1} a+\boldsymbol{Z}_{2} f+\boldsymbol{Z}_{3} c$, from Eq. (1), which is related to the CRCF strategy with genetic gains predicted by $\Delta G_{H_{\overline{\mathrm{CL}}}^{2}}$. The mean of $\Delta G$ across the ten repetitions was calculated for each strategy/family-size combination. ASReml-R4 was used to conduct the simulations (Butler et al. 2017).

\section{Results}

\subsection{Distribution of genetic variance components}

Estimates of variance components and genetic parameters for growth and wood quality traits, obtained from four full-sib and two half-sib clonal trials, are presented in Tables 3 and 4. In the full-sib clonal trials, additive genetic variance $\left(\hat{V}_{\mathrm{A}}\right)$ accounted for 45.1 to $67.8 \%$ of the total genetic variance for the different traits. Dominance variance estimates $\left(\hat{V}_{\mathrm{D}}\right)$ were zero for most traits but $\mathrm{DBH}_{12}$ and Pilo $_{12}$ which had $\hat{V}_{\mathrm{D}}$ estimates accounting for $10.6 \%$ and $54.5 \%$ of the total genetic variation, respectively, and their standard errors were larger than their variance components. Epistatic variance estimates of $\mathrm{HT}_{6}, \mathrm{DBH}_{12}$, and $\mathrm{VOL}_{12}$ varied from 32.2 to $55.2 \%$ of the total genetic variance for the different traits while $\mathrm{HT}_{12}$ and Pilo $_{12}$ showed no epistatic genetic variation at all. For traits measured at multiple sites, additive-by-location interaction effects $\left(\sigma_{A x L}^{2}\right)$, SCA-by-location interaction effects $\left(\sigma_{\mathrm{SCAxL}}^{2}\right)$, and clone within family-by-location interaction effects $\left(\sigma_{C x L}^{2}\right)$ explained only small amounts of the phenotypic variances $(0.0-1.8 \%)$.

In the two half-sib clonal trials, all growth traits $\left(\mathrm{HT}_{3}, \mathrm{HT}_{6}\right.$, $\mathrm{HT}_{13}, \mathrm{DBH}_{13}, \mathrm{DBH}_{25}$, and $\mathrm{VOL}_{13}$ ) showed non-additive genetic variance estimates $\left(\hat{V}_{\mathrm{N}}\right)$ that are higher than the corresponding additive genetic variances. For example, $\hat{V}_{\mathrm{N}}$ for $\mathrm{HT}_{6}$ accounted for $64.2 \%$ of the total genetic variance, which was close to twice the additive variance $(35.8 \%)$. For wood quality traits, $\hat{V}_{\mathrm{N}}$ was estimated at zero, except for $\operatorname{Resi}_{25}$ where $\hat{V}_{\mathrm{N}}$ accounted for $29.0 \%$ of the total genetic variance. For growth traits, percentages of the additive-by-site variance $\sigma_{A x L}^{2}(4.7-7.4 \%)$ were higher than the corresponding percentages for the full-sib trials $(0.6-1.8 \%)$. The residual variance component was the largest source of variation in both full-sib and half-sib clonal trials for all traits, accounting for $78.6-87.8 \%$ of the phenotypic variance for growth traits and $47.4-61.6 \%$ of the phenotypic variance for wood quality traits.

Table 3 Additive, dominance, and epistatic genetic variances of observed traits in four full-sib clonal trials

\begin{tabular}{|c|c|c|c|c|c|c|c|c|c|c|}
\hline \multirow[t]{2}{*}{ Source } & \multicolumn{2}{|l|}{$\mathrm{HT}_{6}(\mathrm{dm})$} & \multicolumn{2}{|l|}{$\mathrm{HT}_{12}{ }^{*}(\mathrm{dm})$} & \multicolumn{2}{|c|}{$\mathrm{DBH}_{12}(\mathrm{~mm})$} & \multicolumn{2}{|c|}{$\operatorname{VOL}_{12}^{*}\left(\mathrm{dm}^{3}\right)$} & \multicolumn{2}{|c|}{$\mathrm{Pilo}_{12}{ }^{*}(\mathrm{~mm})$} \\
\hline & Est (SE) & $\%$ & Est (SE) & $\%$ & Est (SE) & $\%$ & Est (SE) & $\%$ & Est (SE) & $\%$ \\
\hline Mean & 26.6 & & 67.2 & & 82.1 & & 22.7 & & 19.2 & \\
\hline$\sigma_{A}^{2}$ & $3.8(1.2)$ & 6.9 & $13.0(4.6)$ & 5.5 & $32.2(18.6)$ & 6.6 & $13.9(4.5)$ & 8.0 & $1.0(0.9)$ & 20.4 \\
\hline$\sigma_{S}^{2}$ & 0.0 & 0.0 & 0.0 & 0.0 & $1.6(6.6)$ & 0.3 & 0.0 & 0.0 & $0.3(0.4)$ & 6.1 \\
\hline$\sigma_{C}^{2}$ & $3.3(0.7)$ & 6.0 & $15.9(4.5)$ & 6.8 & $26.3(9.9)$ & 5.4 & $6.6(3.3)$ & 3.8 & $0.6(0.4)$ & 12.2 \\
\hline$\sigma_{A^{*} L}^{2}$ & $1.0(0.3)$ & 1.8 & & & $2.7(2.6)$ & 0.6 & & & & \\
\hline$\sigma_{S C A * L}^{2}$ & 0.0 & 0.0 & & & $3.4(5.1)$ & 0.7 & & & & \\
\hline$\sigma_{C * L}^{2}$ & $1.0(0.3)$ & 1.8 & & & $1.2(4.6)$ & 0.2 & & & & \\
\hline$\sigma_{e}^{2}$ & $46.2(0.7)$ & 83.4 & $206.7(5.4)$ & 87.8 & $419.3(6.3)$ & 86.2 & $154.2(4.0)$ & 88.2 .0 & $3.0(0.1)$ & 61.2 \\
\hline \multicolumn{11}{|c|}{ Partitioning of genetic components of variances and their percentage ratios of the total genetic variance $\left(\hat{V}_{\mathrm{G}}\right)$} \\
\hline$\hat{V}_{\mathrm{A}}$ & $3.8(1.2)$ & 53.5 & $13(4.6)$ & 45.1 & $32.2(18.6)$ & 53.6 & $13.9(4.5)$ & 67.8 & $1.0(0.9)$ & 45.5 \\
\hline$\hat{V}_{\mathrm{D}}$ & 0.0 & 0.0 & 0.0 & 0.0 & $6.4(26.0)$ & 10.6 & 0.0 & 0.0 & $1.2(1.4)$ & 54.5 \\
\hline$\hat{V}_{\mathrm{I}}$ & $3.3(0.7)$ & 46.5 & $15.9(4.5)$ & 55.2 & $21.5(13.7)$ & 35.8 & $6.6(3.6)$ & 32.2 & $-0.3(0.7)$ & 0.0 \\
\hline$\hat{\nabla}_{\mathrm{G}}$ & $7.1(0.7)$ & 100 & $28.9(4.4)$ & 100 & $60.1(6.6)$ & 100 & 20.5 & 100 & $1.9(0.2)$ & 100 \\
\hline
\end{tabular}

*The results were based on the single-site S1387. Standard errors for parameter estimates at zero are not available due to ASReml parameter restrictions 
Table 4 Additive, dominance, and epistatic genetic variances of observed traits in two half-sib clonal trials

\begin{tabular}{|c|c|c|c|c|c|c|c|c|c|c|}
\hline \multirow[t]{2}{*}{ Source } & \multicolumn{2}{|l|}{$\mathrm{HT}_{3}(\mathrm{dm})$} & \multicolumn{2}{|l|}{$\mathrm{HT}_{6}(\mathrm{dm})$} & \multicolumn{2}{|l|}{$\mathrm{HT}_{13} *(\mathrm{dm})$} & \multicolumn{2}{|c|}{$\mathrm{DBH}_{13}(\mathrm{~mm})$} & \multicolumn{2}{|l|}{$\mathrm{DBH}_{25}(\mathrm{~mm})$} \\
\hline & Est (SE) & $\%$ & Est (SE) & $\%$ & Est (SE) & $\%$ & Est (SE) & $\%$ & Est (SE) & $\%$ \\
\hline Mean & \multicolumn{2}{|l|}{5.9} & \multicolumn{2}{|l|}{15.6} & \multicolumn{2}{|l|}{59.8} & \multicolumn{2}{|l|}{62.8} & \multicolumn{2}{|l|}{123.4} \\
\hline$\sigma_{A}^{2}$ & $11.5(5.3)$ & 5.3 & $97.0(55.8)$ & 4.1 & $11.4(3.2)$ & 7.5 & $13.5(8.0)$ & 4.0 & $31.8(35.0)$ & 3.0 \\
\hline$\sigma_{N}^{2}$ & $22.7(5.1)$ & 10.5 & $174.0(54.9)$ & 7.4 & $12.3(3.1)$ & 8.1 & $24.7(7.9)$ & 7.3 & $63.1(37.1)$ & 5.9 \\
\hline$\sigma_{A x L}^{2}$ & $10.1(4.4)$ & 4.7 & $124.7(52.0)$ & 5.3 & & & $18.0(7.6)$ & 5.3 & $79.1(41.0)$ & 7.4 \\
\hline$\sigma_{N * L}^{2}$ & $1.7(4.4)$ & 0.8 & $72.8(53.5)$ & 3.1 & & & $9.8(7.8)$ & 2.9 & $6.9(42.9)$ & 0.6 \\
\hline$\sigma_{e}^{2}$ & $169.7(3.0)$ & 78.6 & $1880.7(31.1)$ & 80.1 & $128.0(2.2)$ & 84.4 & $273.5(4.4)$ & 80.6 & $893.4(23.4)$ & 83.2 \\
\hline \multicolumn{11}{|c|}{ Partitioning of genetic components of variances and their percentage ratios of the total genetic variance $\left(\hat{V}_{\mathrm{G}}\right)$} \\
\hline$\hat{V}_{\mathrm{A}}$ & $11.5(5.3)$ & 33.6 & $97(55.7)$ & 35.8 & $11.4(3.2)$ & 48.1 & $13.5(8.0)$ & 35.3 & $31.8(34.8)$ & 33.5 \\
\hline$\hat{V}_{\mathrm{N}}$ & $22.7(5.1)$ & 66.4 & $174(54.9)$ & 64.2 & $12.3(3.1)$ & 51.9 & $24.7(7.9)$ & 64.7 & $63.1(37.2)$ & 66.5 \\
\hline$\hat{\nabla}_{\mathrm{G}}$ & $34.3(2.9)$ & 100 & $271(31.8)$ & 100 & $23.7(1.8)$ & 100 & $38.2(4.6)$ & 100 & $94.9(23.9)$ & 100 \\
\hline \multirow[t]{2}{*}{ Source } & \multicolumn{2}{|c|}{$\mathrm{VOL}_{13} *\left(\mathrm{dm}^{3}\right)$} & \multicolumn{2}{|l|}{$\mathrm{MOE}_{25}(\mathrm{GPa})$} & \multicolumn{2}{|l|}{$\operatorname{Resi}_{25} *$} & \multicolumn{2}{|c|}{ Pilo $_{25} *(\mathrm{~mm})$} & \multicolumn{2}{|l|}{$\mathrm{AV}_{25}(\mathrm{~km} / \mathrm{s})$} \\
\hline & Est (SE) & $\%$ & Est(SE) & $\%$ & Est (SE) & $\%$ & Est (SE) & $\%$ & Est (SE) & $\%$ \\
\hline Mean & 14.6 & & 10.7 & & 18.1 & & 17.9 & & 4.2 & \\
\hline$\sigma_{A}^{2}$ & $6.2(1.7)$ & 8.5 & $1.5(0.1)$ & 39.5 & $1680.5(389.9)$ & 35.1 & $1.6(0.1)$ & 43.4 & $0.018(0.002)$ & 29.1 \\
\hline$\sigma_{N}^{2}$ & $7.9(1.6$ & 10.9 & 0.0 & 0.0 & $685.3(320.2)$ & 14.3 & 0.0 & 0.0 & 0.0 & 0.0 \\
\hline$\sigma_{A x L}^{2}$ & & & $0.3(0.1)$ & 7.9 & & & & & $0.057(0.001)$ & 9.3 \\
\hline$\sigma_{N^{*} L}^{2}$ & & & $0.2(0.1)$ & 5.3 & & & & & 0.0 & 0.0 \\
\hline$\sigma_{e}^{2}$ & $58.0(1.0)$ & 80.6 & $1.8(0.1)$ & 47.4 & $2415.8(78.1)$ & 50.5 & $2.1(0.1)$ & 56.6 & $0.038(0.002)$ & 61.6 \\
\hline \multicolumn{11}{|c|}{ Partitioning of genetic components of variances and their percentage ratios of the total genetic variance $\left(\hat{V}_{\mathrm{G}}\right)$} \\
\hline$\hat{\nabla}_{\mathrm{A}}$ & $6.2(1.7)$ & 43.9 & $1.5(0.1)$ & 100 & $1680.5(389.9)$ & 71 & $1.6(0.1)$ & 100 & $0.018(0.002)$ & 100 \\
\hline$\hat{\nabla}_{\mathrm{N}}$ & $7.9(1.3)$ & 56.1 & 0.0 & 0.0 & $685.3(320.2)$ & 29 & 0.0 & 0.0 . & 0.0 & 0.0 \\
\hline$\hat{V}_{\mathrm{G}}$ & $14.0(0.9)$ & 100 & $1.5(0.1)$ & 100 & $2365.8(148.5)$ & 100 & $1.6(0.1)$ & 100 & $0.018(0.002)$ & 100 \\
\hline
\end{tabular}

*The results were based on a single site. Standard errors for parameters estimates at zero are not available due to ASReml parameter restrictions

\subsection{Heritability}

Five types of heritabilities for different traits are shown in Tables 5 and 6 for full-sib and half-sib clonal trials, respectively. In the full-sib and half-sib clonal trials, clonal mean heritability $\left(H_{\overline{\mathrm{CL}}}^{2}\right)$ estimates were always larger than individual-tree narrow-sense $\left(h^{2}\right)$ and broad-sense $\left(H^{2}\right)$ heritabilities for all traits. $H_{\overline{\mathrm{CL}}}^{2}$ varied from 0.22 for $\mathrm{DBH}_{25}$ to 0.66 for Resi $i_{25}$ (Tables 5 and 6) and $h^{2}$ varied from 0.03 for $\mathrm{DBH}_{25}$ to 0.43 for $\mathrm{Pilo}_{25}$, while $H^{2}$ varied from 0.09 for $\mathrm{DBH}_{25}$ to 0.49 for $\operatorname{Resi}_{25}$. The $h^{2}$ estimates of most wood quality traits including AV, Resi, Pilo, and MOE (0.21-0.43) were systematically higher than those of growth traits (0.03-0.09).

In full-sib clonal trials, both half-sib $\left(H_{\overline{\mathrm{HS}}}^{2}\right)$ and full-sib $\left(H_{\overline{\mathrm{FS}}}^{2}\right)$ family mean heritabilities were usually higher than $H_{\overline{\mathrm{CL}}}^{2}$ estimates, except for $\mathrm{Pilo}_{12}$ where the $H_{\overline{\mathrm{CL}}}^{2}$ estimate (0.63) was higher than $H_{\overline{\mathrm{HS}}}^{2}(0.58)$. For growth traits measured only in a single full-sib trial $\left(\mathrm{HT}_{12}\right.$ and $\left.\mathrm{VOL}_{12}\right)$, estimates of $H_{\overline{\mathrm{HS}}}^{2}$ and $H_{\overline{\mathrm{FS}}}^{2}$ were more than twice as high as those of $H_{\overline{\mathrm{CL}}}^{2}$. In half-sib clonal trials, however, $H_{\overline{\mathrm{HS}}}^{2}$ estimates for growth traits $(0.19-0.49)$ were lower than the corresponding $H_{\overline{\mathrm{CL}}}^{2}$

Table 5 Estimates of individual-tree narrow-sense heritability $\left(h^{2}\right)$, broad-sense heritability $\left(H^{2}\right)$, half-sib and full-sib family mean heritabilities $\left(H_{\overline{\mathrm{HS}}}^{2}\right.$ and $H_{\overline{\mathrm{FS}}}^{2}$ ), and clone mean heritability for different traits measured in four full-sib clonal trials

\begin{tabular}{llllll}
\hline & $\mathrm{HT}_{6}$ & $\mathrm{HT}_{12} *$ & $\mathrm{DBH}_{12}$ & $\mathrm{VOL}_{12} *$ & $\mathrm{Pilo}_{12} *$ \\
\hline$h^{2}$ & $0.07(0.02)$ & $0.06(0.02)$ & $0.07(0.04)$ & $0.08(0.02)$ & $0.21(0.17)$ \\
$H^{2}$ & $0.13(0.01)$ & $0.12(0.02)$ & $0.12(0.01)$ & $0.12(0.02)$ & $0.38(0.03)$ \\
$H_{\overline{\mathrm{HS}}}^{2}$ & $0.84(0.04)$ & $0.73(0.07)$ & $0.77(0.36)$ & $0.81(0.05)$ & $0.58(0.43)$ \\
$H_{\overline{\mathrm{FS}}}^{2}$ & $0.90(0.03)$ & $0.72(0.07)$ & $0.87(0.04)$ & $0.79(0.05)$ & $0.92(0.02)$ \\
$H_{\overline{\mathrm{CL}}}^{2}$ & $0.60(0.03)$ & $0.28(0.03)$ & $0.57(0.03)$ & $0.04)$ & $0.63(0.03)$ \\
\hline
\end{tabular}

Note: Standard error for each type of heritabilities is shown in parenthesis

* The results were based on a single site 
Table 6 Estimates of individual-tree narrow-sense heritability $\left(h^{2}\right)$, broad-sense heritability $\left(H^{2}\right)$, half-sib family mean heritaiblities $\left(H_{\overline{\mathrm{HS}}}^{2}\right)$, and clone mean heritability $\left(H_{\overline{\mathrm{CL}}}^{2}\right)$ for different traits measured in two half-sib clonal trials

\begin{tabular}{lllllllllll}
\hline & $\mathrm{HT}_{3}$ & $\mathrm{HT}_{6}$ & $\mathrm{HT}_{13} *$ & $\mathrm{DBH}_{13}$ & $\mathrm{DBH}_{25}$ & $\mathrm{VOL}_{13} *$ & $\mathrm{AV}_{25}$ & $\mathrm{MOE}_{25}$ & $\mathrm{Resi}_{25} *$ & $\mathrm{Pilo}_{25} *$ \\
\hline$h^{2}$ & $0.05(0.02)$ & $0.04(0.02)$ & $0.07(0.02)$ & $0.04(0.02)$ & $0.03(0.03)$ & $0.09(0.02)$ & $0.29(0.02)$ & $0.40(0.02)$ & $0.35(0.08)$ & $0.43(0.03)$ \\
$H^{2}$ & $0.16(0.01)$ & $0.12(0.01)$ & $0.16(0.01)$ & $0.11(0.01)$ & $0.09(0.02)$ & $0.19(0.01)$ & $0.29(0.02)$ & $0.40(0.02)$ & $0.49(0.02)$ & $0.43(0.03)$ \\
$H_{\overline{\mathrm{HS}}}^{2}$ & $0.32(0.11)$ & $0.28(0.13)$ & $0.45(0.07)$ & $0.27(0.13)$ & $0.19(0.18)$ & $0.47(0.07)$ & $0.59(0.03)$ & $0.66(0.03)$ & $0.74(0.05)$ & $0.56(0.01)$ \\
$H_{\overline{\mathrm{CL}}}^{2}$ & $0.53(0.04)$ & $0.38(0.04)$ & $0.42(0.02)$ & $0.37(0.04)$ & $0.22(0.05)$ & $0.50(0.02)$ & $0.52(0.03)$ & $0.59(0.03)$ & $0.66(0.02)$ & $0.64(0.03)$ \\
\hline
\end{tabular}

Note: Standard error for each type of heritabilities is shown in parenthesis

* The results were based on a single site

estimates (0.22-0.53), except for $\mathrm{HT}_{13}$ measured at a single site. In contrast, several wood quality traits, such as $\mathrm{AV}_{25}$, $\mathrm{MOE}_{25}$, and $\mathrm{Resi}_{25}$, showed that $H_{\overline{\mathrm{HS}}}^{2}$ estimates (0.56-0.74) are systematically higher than the corresponding $H_{\overline{\mathrm{CL}}}^{2}$ estimates (0.52-0.66).

\subsection{Genetic gain}

Given a common selection intensity of $1 \%$, the expected genetic gains for different traits under five different selection and deployment strategies are shown in Table 7 and $b$ for full-sib and half-sib clonal trials. In full-sib clonal trials, the expected genetic gain (EGG) achieved by mass selection and grafted orchard (SOPF, $\Delta G_{h^{2}}$ ) ranged from $3.7 \%$ for $\mathrm{HT}_{12}$ to $12.4 \%$ for $\mathrm{VOL}_{12}$. EGGs achieved by mass selection and cloning (CINF, $\Delta$ $G_{H^{2}}$ ) ranged from $7.3 \%$ for $\mathrm{HT}_{12}$ to $18.7 \%$ for $\mathrm{VOL}_{12}$. EGGs by clonal mean selection and cloning (CRCF, $\Delta$ $\left.G_{H_{\overline{C L}}^{2}}\right)$ varied from $11.3 \%$ for $\mathrm{HT}_{12}$ to $27.7 \%$ for $\mathrm{VOL}_{12}$ and were consistently higher than the corresponding EGGs for backward parental (GCA) selection (SHSB, $\Delta G_{H_{\overline{\mathrm{HS}}}^{2}}, 5.3$ to $19.8 \%$ ) and EGGs for backward selection of specific controlled crosses (SFSB, $\Delta G_{H_{\overline{\mathrm{FS}}}^{2}}, 8.6$ to $27.5 \%$ ).

For the half-sib clonal data analyses, $\Delta G_{h^{2}}$ of SOPF varied from $2.1 \%$ for $\mathrm{DBH}_{25}$ to $19.3 \%$ for $\mathrm{MOE}_{25}$. For the CINF strategy, $\Delta G_{H^{2}}$ varied from $4.5 \%$ for $\mathrm{AV}_{25}$ to $29.5 \%$ for $\mathrm{VOL}_{13}$. Finally EGGs for the CRCF strategy $\left(\Delta G_{H_{\overline{\mathrm{CL}}}^{2}}\right)$ varied from $6.1 \%$ for $\mathrm{AV}_{25}$ to $48.5 \%$ for $\mathrm{VOL}_{13}$ and were systematically higher than the EGGs for all other strategies available for half-sib clonal trials (SOPF, CINF, and SHSB).

\subsection{The optimal family size to capture the most clonal gain}

To detect the optimal family size considering both genetic gain and the maintenance of genetic diversity at deployment, additional predictions of the genetic gain for $\mathrm{DBH}_{12}$ were made based on four putative selection scenarios. The results of this subsampling and selection response predictions are shown in Fig. 1. The realized genetic gain (RGG) achievable decreased from scenario 1 to scenario 4 irrespective of family size but the scenarios exhibited similar trends where the genetic gain increased by an increasing number of available clones per family. The RGG using scenario 1 increased quickly from $15.1 \%$ when five clones were available per family to $19.7 \%$ when 25 clones/family were available and then a slight further increase to $20.1 \%$ when 40 clones/family were available. To consider diversity for deployment using scenarios 3 and 4 compared with scenarios 1 and 2, the RGG decreased, especially for scenario 4 which imposed restrictions on the co-ancestry between selected individuals.

Table 7 Expected genetic gains (\%) for different deployment strategies and different traits measured in four full-sib clonal trials where the selection intensity was $i=2.67$ ( $1 \%$ of the population selected)

\begin{tabular}{|c|c|c|c|c|c|}
\hline Strategy and gain type & $\mathrm{HT}_{6}$ & $\mathrm{HT}_{12} *$ & $\mathrm{DBH}_{12}$ & $\mathrm{VOL}_{12} *$ & Pilo $_{12} *$ \\
\hline SOPF, $\Delta G_{h^{2}}$ & 5.2 & 3.7 & 5.0 & 12.4 & 6.5 \\
\hline CINF, $\Delta G_{H^{2}}$ & 9.7 & 7.3 & 8.6 & 18.7 & 11.7 \\
\hline $\mathrm{SHSB}, \Delta G_{H_{-}^{2}}$ & 9.0 & 6.1 & 8.1 & 19.8 & 5.3 \\
\hline SFSB, $\Delta G_{H_{\overline{S E}}^{2}}{ }^{2}$ & 13.2 & 8.6 & 12.8 & 27.5 & 12.0 \\
\hline CRCF, $\Delta G_{H_{\overline{\mathrm{CL}}}^{2}}^{\mathrm{FS}}$ & 20.8 & 11.3 & 19.0 & 27.7 & 15.0 \\
\hline
\end{tabular}

*The results were based on a single site 


\section{Discussion}

\subsection{Partitioning of genetic variances and genetic parameters}

Traditionally, partitioning epistasis requires either inbred lines or a vegetatively propagated (clonal) population (Foster and Shaw 1988). In forestry, inbred lines have seldom been used as it is usually prohibitively time-consuming to conduct the required multiple generations of inbreeding in tree species (Russell and Ferguson 2008) due to slower generational turnover rate. Moreover, most tree species are known to exhibit severe inbreeding depression (Eriksson et al. 1973; Wu et al. 2016). Thus, clonal field trials with family structure are a more common method to estimate non-additive, in particular, epistatic genetic variance. Currently, genomic data with numerous markers distributed genome-wide using exome capture (Thistlethwaite et al. 2017; Chen et al. 2019), Genotypingby-sequencing (GBS) (Ratcliffe et al. 2015) or SNP-chips (Tan et al. 2018) are becoming gradually available and genomic relationship matrices for additive, dominance, and epistatic effects can be calculated to estimate the additive, dominance, and epistasis genetic variances. Predicted genomic breeding values can also be compared with the traditional pedigree-based breeding values (Muñoz et al. 2014). Given

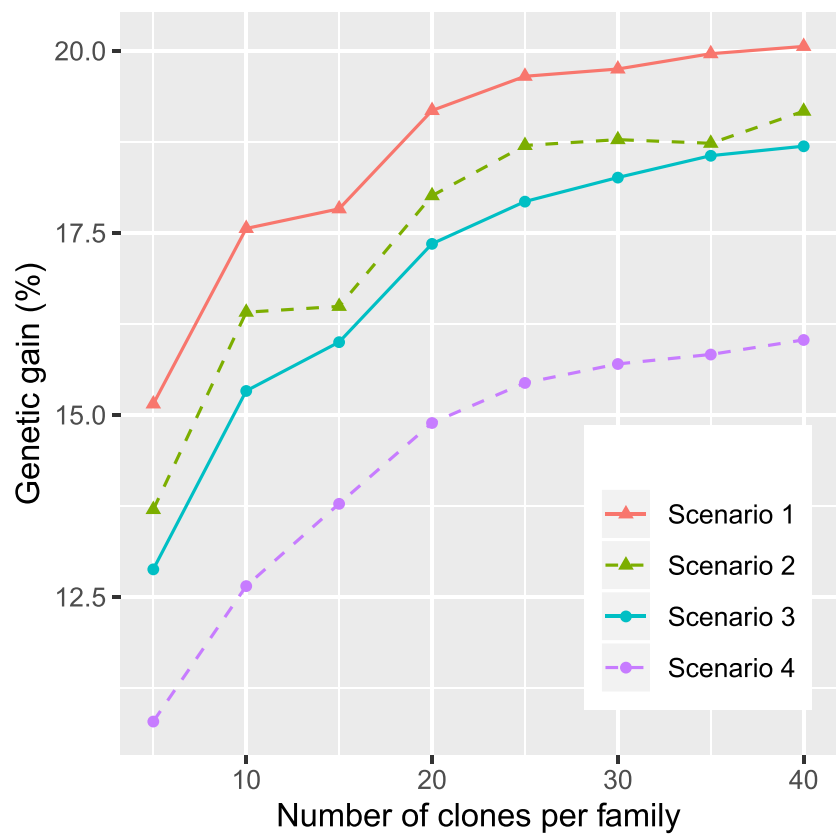

Fig. 1 The trend of genetic gain for $\mathrm{DBH}_{12}$ based on the four selection scenarios: (1) selecting the best ten clones based on genetic values for $\mathrm{DBH}_{12}$ without any constraints with respect to interrelatedness from sampled subsets of clones from the full-sib clonal trials using family sizes ranging from five to 40 clones per family; (2) selecting the single best clone in each of the best ten families from the same sampled subsets; (3) selecting the best 20 clones irrespective of family; and (4) selecting the single best clone in each of the best 20 families a multitude of markers, all genetic effects could be estimated and dissected even using a simple half-sib progeny trial of large enough sample size. However, so far, experiments were usually not large in genomic studies with a limited number of individuals within family sampled; the estimates are not accurate enough for studying various deployment strategies.

\subsubsection{Growth traits}

In this study, large clonal trials with half-sib and full-sib family structures were used to partition the total genetic variance into its basic components $\left(V_{\mathrm{A}}, V_{\mathrm{D}}\right.$, and $\left.V_{\mathrm{I}}\right)$. We found that $V_{A}$ accounted for a large proportion of the total genetic variance (45.1-67.8\% in full-sib clonal trials and $33.5-48.1 \%$ in halfsib trials), indicating that the use of breeding values can capture considerable additive genetic gain. For growth traits in full-sib clonal trials, only DBH showed a small amount of $V_{\mathrm{D}}$ $(10.6 \%)$ in relation to $V_{\mathrm{G}}$, but epistatic effects accounted for a considerable amount of the total genetic variance (32.2$55.2 \%$, with large standard errors), indicating that the use of clonal deployment strategies (CRCF and maybe also CINF) could greatly improve genetic gain compared with the deployment of seedlings where $V_{\mathrm{A}}$ (SOPF and SHSB) plus, at best, a fraction of $V_{\mathrm{D}}(\mathrm{SFSB})$ can be exploited. In contrast, Chen et al. (2019) used both pedigree-based and genomic-based relationship matrices to estimate all genetic effects in Norway spruce and could not find any epistatic variance at all for tree height but instead obtained a considerable $V_{\mathrm{D}}$ estimate. The result of our study suggests, however, that $V_{\mathrm{I}}$ for growth traits in Norway spruce is much more important than $V_{\mathrm{D}}$ in line with other studies such as in white spruce (Picea glauca (Moench) Voss) by Weng et al. (2008) and black spruce (Picea mariana (Mill.) B.S.P) by Mullin and Park (1994). In a radiata pine (Pinus radiata L.) study, DBH at age 5 years showed a large amount of epistatic variance $(35.7 \%)$ in relation to $V_{\mathrm{G}}$ (Baltunis et al. 2009). In a loblolly pine (Pinus taeda D. Don) study, however, the tree height at age 2 in six trials exhibited a negative estimate of epistasis (Baltunis et al. 2007). In a disconnected partial diallels of coastal Douglas fir (Pseudotsuga menziesii var. menziesii DOUGL.) progeny study, Yanchuk (1996) reported that $V_{\mathrm{D}} / V_{\mathrm{A}}$ varied from 75 to $260 \%$ for three growth traits. The relative comparison of the $V_{\mathrm{D}}$ and $V_{\mathrm{I}}$ estimates of our study should be interpreted with caution because the full-sib trial design offered only a limited representation of crosses for each investigated parent (on average 1.3 crosses per parent) and very high standard error thereby making an accurate estimation of $V_{\mathrm{D}}$ difficult. In conclusion, the non-additive effects seem to be an important part for growth traits and comparable with additive effects in Norway spruce, but the relative amount of variance for dominance and epistatic effects may change with the population, and their size, and the number of full-sib within a test population, and species. 
Table 8 Expected genetic gains (\%) for different deployment strategies and different traits measured in two half-sib clonal trials where the selection intensity was $i=2.67$ ( $1 \%$ of the population selected)

\begin{tabular}{|c|c|c|c|c|c|c|c|c|c|c|}
\hline Strategy and gain type & $\mathrm{HT}_{3}$ & $\mathrm{HT}_{6}$ & $\mathrm{HT}_{13} *$ & $\mathrm{DBH}_{13}$ & $\mathrm{DBH}_{25}$ & $\mathrm{VOL}_{13} *$ & $\mathrm{AV}_{25}$ & $\mathrm{MOE}_{25}$ & $\operatorname{Resi}_{25} *$ & $\mathrm{Pilo}_{25} *$ \\
\hline SOPF, $\Delta G_{h^{2}}$ & 3.3 & 3.3 & 4.1 & 3.1 & 2.1 & 14.0 & 4.5 & 19.3 & 10.7 & 12.3 \\
\hline CINF, $\Delta G_{H^{2}}$ & 10.6 & 9.9 & 8.6 & 8.6 & 6.4 & 29.5 & 4.5 & 19.3 & 15.0 & 12.3 \\
\hline SHSB, $\Delta G_{H^{2}}$ & 4.4 & 4.5 & 5.1 & 4.1 & 2.7 & 15.7 & 3.2 & 12.3 & 7.8 & 7.8 \\
\hline CRCF, $\Delta G_{H_{\overline{\mathrm{CL}}}^{2}}^{\mathrm{HS}}$ & 19.3 & 17.3 & 14.2 & 16.0 & 10.0 & 48.5 & 6.1 & 23.4 & 17.4 & 15.1 \\
\hline
\end{tabular}

*The results were based on a single site

\subsubsection{Wood quality traits}

For the wood quality traits on three sites, Pilo in full-sib clonal trials and Resi in half-sib clonal trials showed some appreciable non-additive genetic effects (Table 8). Pilo in the full-sib clonal trials showed a $V_{\mathrm{D}}$ estimate that accounted for $54.5 \%$ of the total genetic variance but in the two half-sib clonal trials, the non-additive genetic variance for Pilo was estimated at zero. In Eucalyptus, Costa e Silva et al. (2004) reported that epistatic effects explained $22.7 \%$ of the total genetic variation for Pilo while dominance genetic effects explained no variation at all. In this study, we did not observe any non-additive effects for acoustic velocity (AV). In contrast, Chen et al. (2019) found small but appreciable dominance and epistatic effects for AV in two full-sib progeny trials of Norway spruce in northern Sweden. It seems there was less non-additive genetic variance in wood quality traits than in growth traits in Norway spruce as similarly observed in other pines (Wu et al. 2008), which may partly be a result of less field environmental error or nursery treatment effects (e.g., sizes of cutting or positions of ortet influence, one of $\mathrm{C}$ effects (Burdon and Shelbourne 1974) in forestry) affecting the wood properties compared with growth traits.

\subsection{Heritability}

Both narrow-sense and broad-sense heritabilities are traitspecific and population-specific and are greatly influenced by the homogeneity of the environment containing the genetic test (White et al. 2007). In this study, the individual-tree heritability $\left(h^{2}\right.$ and $\left.H^{2}\right)$ estimates were low for growth traits (0.03-0.09 and 0.09-0.20, respectively), but the large number of clones and families in the full-sib (1430 and 32, respectively) and half-sib (2244 and 138, respectively) trials with low standard errors, nonetheless, indicated that estimates of $h^{2}$ and $H^{2}$ were accurate (Perron et al. 2013). For wood quality traits, moderate estimates of $h^{2}$ and $H^{2}$ were in the ranges $0.21-0.43$ and $0.29-0.49$, respectively, which is in line with a previous study for Norway spruce (Chen et al. 2015). The additive by environmental effect (GEI) was non-significant or low (0$1.8 \%$ ) from the four full-sib trials, resulting in insignificant impact on the estimation of heritability. The GEI were higher
(4.7-9.3\%) in two half-sib trials than the corresponding percentages for the full-sib trials. Such GEI may decrease heritability estimates in the joint-site analyses.

\subsubsection{Heritability of growth traits}

In this study, we used joint-site models to estimate $h^{2}$ and $H^{2}$ for most the growth traits. Moreover, $\mathrm{G} \times \mathrm{E}$ interaction was accounted for by excluding $\mathrm{G} \times \mathrm{E}$ sources of variance in numerator in the equation of heritability estimates in contrast to many other studies for Norway spruce (Hannrup et al. 2004; Kroon et al. 2011). Estimates of $h^{2}$ for tree height were lower (0.04-0.07) than the values of other published results with seedlings using joint-site models for Norway spruce (Chen et al. 2015, 2017; Skrøppa et al. 2015). Estimates of $H^{2}$ for tree height were in the range $0.12-0.16$ which is comparable with other studies, such as 0.13 for tree height at age 6 (excluding $\mathrm{G} \times \mathrm{E}$ ) (Karlsson and Högberg 1998), 0.17-0.29 for tree height at age 9 (including $\mathrm{G} \times \mathrm{E}$ ) (Högberg and Karlsson 1998), 0.25-0.29 for tree height at ages 3 to 10 years (Bentzer et al. 1989), and 0.09-0.43 for tree height at ages 9 to 18 years (including $\mathrm{G} \times \mathrm{E}$ ) (Högberg and Dutkowski 2010), and 0.10 0.22 for height at age 17 (including $G \times E$ ). Compared with those published studies with high prior intense selection in the nursery, the difference here may be that only a slight prior selection was performed and that may produce less bias in the estimation of $h^{2}$ and $H^{2}$. The $H^{2}$ estimates for $\mathrm{DBH}$ (0.09-0.12 from ages 12 to 25$)$ and VOL (0.12-0.19 from ages 12 to 13 ) are also comparable with previously published results (Bentzer et al. 1989) where $H^{2}$ was 0.12 for both $\mathrm{DBH}$ and VOL at the age of 10.

The total genetic variance and $H^{2}$ are expected to be higher than the corresponding additive variance and $h^{2}$ if there is a non-additive genetic variance. In the present study, the ratios of $V_{\mathrm{A}} / V_{\mathrm{G}}$ ranged from 0.34 to $0.68\left(V_{\mathrm{N}} / V_{\mathrm{A}}=\left(V_{\mathrm{D}}+V_{\mathrm{I}}\right) / V_{\mathrm{A}}\right.$, 0.50-1.94) for growth traits (tree height, DBH, and VOL) leaving considerable amounts of genetic variation to be explained by non-additive sources. Kroon et al. (2011) reported slightly higher but still relatively small ratios of $V_{\mathrm{A}} / V_{\mathrm{G}}(0.60$ 0.84 ) using three full-sib clonal trials in Norway spruce. These results indicate that non-additive effects are important for the Norway spruce breeding program. 
In this study, we found that $H_{\overline{\mathrm{CL}}}^{2}$ estimates were lower than numerous corresponding estimates in other conifer species (Mullin and Park 1994; Baltunis et al. 2007, 2009; Weng et al. 2008). The most probable explanation for this discrepancy is that Norway spruce clonal progeny test series in Sweden often only plant approximately 14 ramets per clone, compared with several times this number for test series of other species. Consequently, growth traits that were measured only at a single site, thus encompassing only approximately three ramets per clone. Traits were measured in several trials, such as $\mathrm{HT}_{6}$ in full-sib clonal trials. $H_{\overline{\mathrm{CL}}}^{2}$ estimates for tree height $(0.38-0.60$ for tree aged 3 to 6$)$ were comparable with the other results (Lepistö 1993 0.75-0.78, Bentzer et al. 1988 $0.63-0.95$ for tree aged $1,0.45-0.73$ for tree aged 5), which all excluded $\mathrm{G} \times \mathrm{E}$ effects in the estimate of clonal mean heritability). In our half-sib clonal trials, the $H_{\overline{\mathrm{CL}}}^{2}$ estimate for tree height at age 6 years $(0.38)$ was much lower than that at age 3 (0.55). Compared with the higher $H_{\overline{\mathrm{CL}}}^{2}$ estimate for $\mathrm{HT}_{3}$, we found that higher estimates of $\mathrm{G} \times \mathrm{E}$ interactions $\left(\sigma_{A x L}^{2}\right.$ and $\sigma_{N x L}^{2}$ ) for $\mathrm{HT}_{6}$ as the most probable reason for the lower $H_{\overline{\mathrm{CL}}}^{2}$ estimate of this trait. $\mathrm{C}$ effects in the nursery might increase $H_{\overline{\mathrm{CL}}}^{2}$ at a young age as well. For $\mathrm{HT}_{6}$ that $\sigma_{A x L}^{2} / \sigma_{A}^{2}>1$ and $\sigma_{C x L}^{2} / \sigma_{C}^{2}=0.42$, it suggests that the deployment of such clones in multiple environments, such as in two breeding zones with different requirements of phenology (Berlin et al. 2019), should properly consider $\mathrm{G} \times \mathrm{E}$ interactions.

\subsubsection{Heritability of wood quality traits}

In the present study, $h^{2}$ estimates for wood traits $(0.21-0.45)$ were comparable with those of other published results $(0.15-0.50$, e.g., AV, Pilo, and MOE) (Hallingbäck et al. 2010; Chen et al. 2015). The ratios of $V_{\mathrm{A}} / V_{\mathrm{G}}$ ranged from 0.45 to $1.00\left(V_{\mathrm{N}} / V_{\mathrm{A}}=\left(V_{\mathrm{D}}+V_{\mathrm{I}}\right) /\right.$ $V_{\mathrm{A}}$ at $0.00-0.90$ for wood properties and the values were usually lower than those for growth traits, indicating that non-additive effects would contribute less to the prospective increased gains of wood quality traits in a clonal deployment situation than what would be possible for growth traits.

\subsection{Response for different selection scenarios}

To maximize genetic gain is one of the most important objectives for tree improvement programs. However, accurate predictions of genetic gain require reliable estimates of all parameters (Mullin and Park 1992). In this study, we used $1 \%$ of the available number of clones as the selection intensity implying a selection of 14 and 24 clones from the full-sib and half-sib clonal populations respectively (CRCF strategy). These numbers have been suggested suitable for clonal forestry in order to maintain genetic diversity in Sweden at the stand level (Rosvall et al. 2019). The estimated genetic gains (EGGs) from such a selection were 17.3 to $20.8 \%$ for tree height (if multi-site analyses are considered). These estimates were close to previous estimates for Norway spruce, e.g., $15.0 \%$ and $25.0 \%$ (Karlsson 1993), 11.5-14.8\% for tree height at age 5 years (Bentzer et al. 1988) in Sweden, and 13.1$19.1 \%$ in Finland in the same species (Lepistö 1993). Based on previously published documents, Wu (2018) summarizes that in conifer species, an extra genetic gain of 5-25\% would be possible from clone testing and deployment, effectively doubling that achievable from backward family-based selection strategies (e.g., SHSB and SFSB). Similarly, a study on radiata pine reported $24 \%$ genetic gain, a relative improvement of more than $100 \%$ over family forestry (SFSB) (Baltunis et al. 2009). The differences with respect to estimated extra gains were mainly dependent on the size of the population, the number of tested clones within-family, the accuracy of the progeny testing, and the ratio of additive to nonadditive genetic variances (Wu 2018).

If the top $1 \%$ of replicated clones were selected for vegetative propagation (CRCF), genetic gains for $\mathrm{DBH}$ at age 12 years were estimated to reach $19.0 \%$, a relative improvement of $48.4 \%$ over full-sib family deployment (SFSB) and $134.6 \%$ over half-sib family deployment (SHSB) at the same selection intensity. A $1 \%$ selection of replicated clones would also be doable in practice (14 and 24 clones from full-sib and half-sib-trials, respectively). However, with respect to the backward family selection strategies (SFSB, SHSB), it should be noted that in the Swedish breeding program, each breeding population comprise only 50 parents and 50 crosses on average. Thus, a $1 \%$ selection intensity would imply a single family being selected and deployed as family forestry which would not be practicable from the point of genetic diversity unless several breeding zones were combined as a single seed orchard. However, for deployment, each seed orchard is usually established with ca. 16-20 parents/clones, thus producing 16-20, or even more, half-sib or full-sib families for deployment (Lindgren and Prescher 2005). For SFSB and SHSB strategies, a realistic selection intensity would be ca. $32-40 \%$ ( $i$ in the range $1.12-1.40)$ rather than $1 \%(i=2.67)$. Thus, from a practical point of view, the relative superiority of $\mathrm{CRCF}$ in comparison with SFSB and SHSB would likely be greater in terms of genetic gain than the apparent theoretical estimates shown in Table 7.

In order to estimate the optimal family size for the clonal deployment of the best-selected clones (CRCF strategy), genetic gains were estimated by simulations and clones were sampled into prospective subsets. Genetic gains predicted from this procedure are therefore better comparable with $\Delta$ $G_{H_{\overline{\mathrm{CL}}}^{2}}$ rather than to $\Delta G_{H^{2}}$. We found that the realized genetic gain from clonal propagation will be maximized given the availability of 30-40 clones per family, which is also the current Swedish operational design in clonal tests of Norway spruce, both with respect to selecting the best ten/20 clones without any restrictions on the relationships among the 
selected clones and the best single clone from the best ten/20 families. The maximum realized genetic gain was then found to be $20.2 / 18.9 \%$ and $19.3 / 16.2 \%$ for each selection scenario, respectively. To consider the genetic diversity, a deep simulation based on the current data could be done in the future as other studies (Rosvall et al. 1998; Weng et al. 2010). The study of genomic selection (GS) has been conducted currently in many commercial tree species, such as Norway spruce (Chen et al. 2018), white spruce, loblolly pine, radiate pine, Maritime pine (Bartholomé et al. 2016; Isik et al. 2016), and Eucalyptus (Resende et al. 2012; Denis and Bouvet 2013; Tan et al. 2017), but focusing on the seedling progeny trials. If a prospective deployment strategy would entail the establishment of a conventional Norway spruce clonal field test in combination with SE technology (Egertsdotter 2019), the whole process would require ca. 14 years in Sweden, including a nursery stage ( 2 years), a field test (10 years), and an additional nursery stage (2 years) with implying an annual genetic gain of $1.4 \%$ using replicated clonal selection (CRCF). However, it should be noted that if GS methods were applied for clonal forestry, then the process would only require 2 years in the nursery to make rooted cuttings with the maximum two additional months in the laboratory for DNA extraction and genotyping. In such a GS scenario, the annual genetic gain would instead be about $9 \%$ if we consider that GS has the same accuracy as a traditional pedigree-based selection. Furthermore, if somatic embryogenesis using cryostorage could be combined with GS, then the time required by the process could be further reduced from 2 years to 6 months in the nursery stage.

\section{Conclusions}

The aim of clonal deployment in forestry is to utilize nonadditive genetic effects plus the fact that individual clones can be replicated and therefore better tested in the field. The estimates of genetic parameters and genetic gain for different traits will assist the design of clonal forestry and guide the Norway spruce clonal deployment strategy. Here we conclude that:

1) Both additive and non-additive genetic variances seem to be almost equally important for Norway spruce growth traits.

2) Both individual-tree heritabilities $h^{2}$ and $H^{2}$ were higher for wood quality traits (Resi, Pilo, $\mathrm{AV}$, and MOE) than for the corresponding heritabilities for growth traits. $H_{\overline{\mathrm{CL}}}^{2}$-estimates based on clonal means were always the largest in magnitude in comparison with $h^{2}$ and $H^{2}$ for all studied traits.

3) The generation of 30-40 clones per full-sib family will assure the maximum realized genetic at future clonal propagation following a selection scenario of either selecting the best ten/20 clone from the population (no restrictions on co-ancestry) or selecting the single best clone from the best ten/20 families.

4) In most cases, the predicted genetic gains using clonal deployment based on clonal mean selection (CRCF) yielded the largest genetic gains, followed by the deployment of specific full-sib families (SFSB) and seedling deployments based on open-pollinated selected parents (SHSB) or selected individuals (SOPF). If the top $1 \%$ of replicated clones were selected for vegetative propagation (CRCF), genetic gains for DBH at age 12 years were estimated to reach $19.0 \%$, a relative improvement of $48.4 \%$ over full-sib family deployment (SHSB), and $134.6 \%$ over half-sib family deployment (SFSB) at the same selection intensity.

Acknowledgments We thank Dr. Ru Wang, Iker Pardo, and Amara Santiesteban for the help of field assistance. We also thank Ola Rosvall for the comments on an earlier version of the manuscript.

Funding information Open access funding provided by Swedish University of Agricultural Sciences. Financial support was received from Föreningen Skogsträdsförädling (grant number 230-2014-427) and the Swedish Foundation for Strategic Research (SSF, grant number RBP140040).

Data availability The data sets generated and/or analyzed during the current study are available from the corresponding author and Skogforsk on reasonable request.

\section{Compliance with ethical standards}

Conflict of interest The authors declare that they have no conflict of interest.

Open Access This article is licensed under a Creative Commons Attribution 4.0 International License, which permits use, sharing, adaptation, distribution and reproduction in any medium or format, as long as you give appropriate credit to the original author(s) and the source, provide a link to the Creative Commons licence, and indicate if changes were made. The images or other third party material in this article are included in the article's Creative Commons licence, unless indicated otherwise in a credit line to the material. If material is not included in the article's Creative Commons licence and your intended use is not permitted by statutory regulation or exceeds the permitted use, you will need to obtain permission directly from the copyright holder. To view a copy of this licence, visit http://creativecommons.org/licenses/by/4.0/.

\section{References}

Baltunis BS, Huber DA, White TL, Goldfarb B, Stelzer HE (2007) Genetic gain from selection for rooting ability and early growth in vegetatively propagated clones of loblolly pine. Tree Genet Genomes 3:227-238. https://doi.org/10.1007/s11295-006-0058-9

Baltunis BS, Wu HX, Dungey HS, Mullin TJT, Brawner JT (2009) Comparisons of genetic parameters and clonal value predictions from clonal trials and seedling base population trials of radiata pine. 
Tree Genet Genomes 5:269-278. https://doi.org/10.1007/s11295008-0172-y

Bartholomé J, Van Heerwaarden J, Isik F, Boury C, Vidal M, Plomion C, Bouffier L (2016) Performance of genomic prediction within and across generations in maritime pine. BMC Genomics 17:604. https://doi.org/10.1186/s12864-016-2879-8

Bentzer BG, Foster GS, Hellberg AR, Podzorski AC (1988) Genotype × environment interaction in Norway spruce involving three levels of genetic control: seed source, clone mixture, and clone. Can J For Res 18:1172-1181. https://doi.org/10.1139/x88-180

Bentzer BG, Foster GS, Hellbersg AR, Podzorski AC (1989) Trends in genetic and environmental parameters, genetic correlations, and response to indirect selection for 10-year volume in a Norway spruce clonal experiment. Can J For Res 19:897-903

Berlin M, Jansson G, Högberg K-A, Helmersson A (2019) Analysis of non-additive genetic effects in Norway spruce. Tree Genet Genomes 15:42-17. https://doi.org/10.1007/s11295-019-1350-9

Bouvet J-M, Makouanzi G, Cros D, Vigneron P (2016) Modeling additive and non-additive effects in a hybrid population using genomewide genotyping: prediction accuracy implications. Heredity 116 : 146-157

Brandel G (1990) Volume functions for individual trees; Scots pine (Pinus sylvestris), Norway spruce (Picea abies) and birch (Betula pendula \& Betula pubescens)

Burdon RD, Shelbourne CJA (1974) The use of vegetative propagules for obtaining genetic information. N Z J For Sci 4:418-425

Butler DG, Cullis BR, Gilmour AR, Gogel BJ, Thompson R (2017) ASReml-R Reference Manual Version 4. VSN International Ltd, Hemel Hempstead, HP1 1ES, UK

Chen Z-Q, García-Gil MR, Karlsson B, Lundqvist S-O, Olsson L, Wu HX (2014) Inheritance of growth and solid wood quality traits in a large Norway spruce population tested at two locations in southern Sweden. Tree Genet Genomes 10:1291-1303. https://doi.org/10. 1007/s11295-014-0761-x

Chen Z-Q, Karlsson B, Lundqvist S-O, García-Gil MR, Olsson L, Wu HX (2015) Estimating solid wood properties using Pilodyn and acoustic velocity on standing trees of Norway spruce. Ann For Sci 72:499-508. https://doi.org/10.1007/s13595-015-0458-9

Chen Z-Q, Karlsson B, Wu HX (2017) Patterns of additive genotype-byenvironment interaction in tree height of Norway spruce in southern and central Sweden. Tree Genet Genomes 13:25-14. https://doi.org/ 10.1007/s11295-017-1103-6

Chen Z-Q, Baison J, Pan J, Karlsson B, Andersson B, Westin J, GarcíaGil MR, Wu HX (2018) Accuracy of genomic selection for growth and wood quality traits in two control-pollinated progeny trials using exome capture as the genotyping platform in Norway spruce. BMC Genomics 19:946. https://doi.org/10.1186/s12864-018-5256-y

Chen Z-Q, Baison J, Pan J, Westin J, García Gil MR, Wu HX. 2019. Increased prediction ability in Norway spruce trials using a marker $\mathrm{x}$ environment interaction and non-additive genomic selection model. J. of Heredity, esz061, https://doi.org/10.1093/jhered/esz061

Costa e Silva J, Borralho NG, Potts B (2004) Additive and non-additive genetic parameters from clonally replicated and seedling progenies of Eucalyptus globulus. Theor Appl Genet 108:1113-1119. https:// doi.org/10.1007/s00122-003-1524-5

Denis M, Bouvet J-M (2013) Efficiency of genomic selection with models including dominance effect in the context of Eucalyptus breeding. Tree Genet Genomes 9:37-51. https://doi.org/10.1007/ s11295-012-0528-1

Downes GM, Lausberg M, Potts B, Pilbeam D, Bird M, Bradshaw B (2018) Application of the IML Resistograph to the infield assessment of basic density in plantation eucalypts. Aust For 81:177-185

Egertsdotter U (2019) Plant physiological and genetical aspects of the somatic embryogenesis process in conifers. Scand J For Res 34: 360-369. https://doi.org/10.1080/02827581.2018.1441433
Eriksson G, Schelander B, Åkebrand V (1973) Inbreeding depression in an old experimental plantation of Picea abies. Hereditas 73:185-193

Falconer D, Mackay T (1996) Introduction to quantitative genetics. Longman, New York

Foster GS, Shaw DV (1988) Using clonal replicates to explore genetic variation in a perennial plant species. Theor Appl Genet 76:788794. https://doi.org/10.1007/bf00303527

Fundova I, Funda T, Wu HX (2018) Non-destructive wood density assessment of Scots pine (Pinus sylvestris L.) using Resistograph and Pilodyn. PLoS One 13:e204518

Gamal El-Dien O, Ratcliffe B, Klápště J, Porth I, Chen C, El-Kassaby YA (2016) Implementation of the realized genomic relationship matrix to open-pollinated white spruce family testing for disentangling additive from nonadditive genetic effects. G3: Genes, Genom, Genet 6:743-753

Gilmour AR, Gogel BJ, Cullis BR, Welham SJ, Thompson R (2015) ASReml user guide release 4.1. VSN International Ltd, Hemel Hempstead, UK

Hallingbäck HR, Jansson G, Hannrup B (2010) Genetic correlations between spiral grain and growth and quality traits in Picea abies. Can J For Res 40:173-183. https://doi.org/10.1139/x09-173

Hannrup B, Cahalan C, Chantre G, Grabner M, Karlsson B, Le Bayon I, Jones GL, Muller U, Pereira H, Rodrigues JC, Rosner S, Rozenberg P, Wilhelmsson L, Wimmer R (2004) Genetic parameters of growth and wood quality traits in Picea abies. Scand J For Res 19:14-29. https://doi.org/10.1080/02827580310019536

Högberg K-A, Dutkowski GW (2010) Genetic correlations among field trials of Norway spruce clones representing different propagation cycles. Silvae Genet 59:182-189. https://doi.org/10.1515/sg-20100022

Högberg K-A, Karlsson B (1998) Nursery selection of Picea abies clones and effects in field trials. Scand J For Res 13:12-20. https://doi.org/ $10.1080 / 02827589809382957$

Ingvarsson PK, Dahlberg H (2018) The effects of clonal forestry on genetic diversity in wild and domesticated stands of forest trees. Scand J For Res 1-10

Isik K, Kleinschmit J (2005) Similarities and effectiveness of test environments in selecting and deploying desirable genotypes. Theor Appl Genet 110:311-322. https://doi.org/10.1007/s00122-0041840-4

Isik F, Li B, Frampton J (2003) Estimates of additive, dominance and epistatic genetic variances from a clonally replicated test of loblolly pine. For Sci 49:77-88

Isik K, Kleinschmit J, Steiner W (2010) Age-age correlations and early selection for height in a clonal genetic test of Norway Spruce. For Sci 56:212-221

Isik F, Bartholomé J, Farjat A, Chancerel E, Raffin A, Sanchez L, Plomion C, Bouffier L (2016) Genomic selection in maritime pine. Plant Sci 242:108-119. https://doi.org/10.1016/j.plantsci.2015.08. 006

Karlsson B (1993) Twenty years of clonal forestry in Sweden. In Norway spruce provenances and breeding. Proceedings of the IUFRO S2211 symposium in Latvia Rone V, editor Riga: Lativian Forestry Research Institute; $p$ 208-212

Karlsson B, Högberg K (1998) Genotypic parameters and clone x site interaction in clone tests of Norway spruce (Picea abies (L.) Karst.). For Genet 5:21-30

Karlsson B, Wellendorf H, Roulund H, Werner M (2001) Genotype × trial interaction and stability across sites in 11 combined provenance and clone experiments with Picea abies in Denmark and Sweden. Can J For Res 31:1826-1836

Kroon J, Ericsson T, Jansson G, Andersson B (2011) Patterns of genetic parameters for height in field genetic tests of Picea abies and Pinus sylvestris in Sweden. Tree Genet Genomes 7:1099-1111. https://doi. org/10.1007/s11295-011-0398-y 
Lepistö M (1993) Genetic variation, heritability and expected gain of height in Picea abies in 7 to 9-year-old clonal tests. Scand J For Res 8:480-488

Lindgren D, Prescher F (2005) Optimal clone number for seed orchards with tested clones. Silvae Genet 54:80-92

Mullin TJ, Park YS (1992) Estimating genetic gains from alternative breeding strategies for clonal forestry. Can J For Res 22:14-23. https://doi.org/10.1139/x92-003

Mullin TJ, Park YS (1994) Genetic parameters and age-age correlations in a clonally replicated test of black spruce after 10 years. Can J For Res 24:2330-2341. https://doi.org/10.1139/x94-301

Muñoz PR, Resende MFR, Gezan SA, Resende MDV, de los Campos G, Kirst M, Huber D, Peter GF (2014) Unraveling additive from nonadditive effects using genomic relationship matrices. Genetics 198: 1759-1768. https://doi.org/10.1534/genetics.114.171322

Perron M, DeBlois J, Desponts M (2013) Use of resampling to assess optimal subgroup composition for estimating genetic parameters from progeny trials. Tree Genet Genomes 9:129-143. https://doi. org/10.1007/s11295-012-0540-5

Ratcliffe B, El-Dien OG, Klápště J, Porth I, Chen C, Jaquish B, ElKassaby Y (2015) A comparison of genomic selection models across time in interior spruce (Picea engelmannii $\times$ glauca) using unordered SNP imputation methods. Heredity 115:547-555

Resende MDV, Resende MFR, Sansaloni CP, Petroli CD, Missiaggia AA, Aguiar AM, Abad JM, Takahashi EK, Rosado AM, Faria DA, Pappas GJ, Kilian A, Grattapaglia D (2012) Genomic selection for growth and wood quality in Eucalyptus: caspturing the missing heritability and accelerating breeding for complex traits in forest trees. New Phytol 194:116-128. https://doi.org/10.1111/j.1469-8137.2011.04038.x

Rosvall O, Lindgren D, Mullin TJ (1998) Sustainability robustness and efficiency of a multi-generation breeding strategy based on withinfamily clonal selection. Silvae Genet 47:307-320

Rosvall $\mathrm{O}$, Ståhl $\mathrm{P}$, Almqvist C, Anderson B, Berlin M, Ericsson T, Eriksson M, Gregorsson B, Hajek J, Hallander J (2011) Review of the Swedish tree breeding programme

Rosvall O, Bradshaw RHW, Egertsdotter U, Ingvarsson PK, Mullin TJ, Wu H (2019) Using Norway spruce clones in Swedish forestry: implications of clones for management. Scand J For Res 1-48. https://doi.org/10.1080/02827581.2019.1590631

Russell JH, Ferguson DC (2008) Preliminary results from five generations of a western redcedar (Thuja plicata) selection study with selfmating. Tree Genet Genomes 4:509-518. https://doi.org/10.1007/ s11295-007-0127-8

Skrøppa T, Solheim H, Steffenrem A (2015) Genetic variation, inheritance patterns and parent-offspring relationships after artificial inoculations with Heterobasidion parviporum and Ceratosystis polonica in Norway spruce seed orchards and progeny tests. Silva Fenn 49

Tan B, Grattapaglia D, Martins GS, Ferreira KZ, Sundberg B, Ingvarsson PK (2017) Evaluating the accuracy of genomic prediction of growth and wood traits in two Eucalyptus species and their F1 hybrids. BMC Plant Biol 17:110. https://doi.org/10.1186/s12870-017-1059-6

Tan B, Grattapaglia D, Wu HX, Ingvarsson PK (2018) Genomic relationships reveal significant dominance effects for growth in hybrid Eucalyptus. Plant Sci 267:84-93. https://doi.org/10.1016/j.plantsci. 2017.11.011

Thistlethwaite FR, Ratcliffe B, Klápště J, Porth I, Chen C, Stoehr MU, ElKassaby YA (2017) Genomic prediction accuracies in space and time for height and wood density of Douglas-fir using exome capture as the genotyping platform. BMC Genomics 18:930. https://doi. org/10.1186/s12864-017-4258-5

Weng YH, Park YS, Krasowski MJ, Tosh KJ, Adams G (2008) Partitioning of genetic variance and selection efficiency for alternative vegetative deployment strategies for white spruce in Eastern Canada. Tree Genet Genomes 4:809-819. https://doi.org/10.1007/ s11295-008-0154-0

Weng YH, Park YS, Krasowski MJ (2010) Managing genetic gain and diversity in clonal deployment of white spruce in New Brunswick, Canada. Tree Genet Genomes 6:367-376. https://doi.org/10.1007/ s11295-009-0255-4

White TL, Adams WT, Neale DB (2007) Forest genetics. CABI publishing, Cambridge

Wu RL (1996) Detecting epistatic genetic variance with a clonally replicated design: models for low- vs high-order nonallelic interaction. Theor Appl Genet 93:102-109. https://doi.org/10.1007/bf00225734

Wu HX (2018) Benefits and risks of using clones in forestry - a review. Scand J For Res 1-8. https://doi.org/10.1080/02827581.2018. 1487579

Wu HX, Ivković M, Gapare WJ, Matheson AC, Baltunis BS, Powell MB, McRae TA (2008) Breeding for wood quality and profit in radiata pine: a review of genetic parameters. N Z J For Sci 38:56-87

Wu HX, Hallingbäck HR, Sánchez L (2016) Performance of seven tree breeding strategies under conditions of inbreeding depression. G3: Genes, Genom, Genet 6:529-540. https://doi.org/10.1534/g3.115. 025767

Yanchuk A (1996) General and specific combining ability from disconnected partial diallels of coastal Douglas-fir. Silvae Genet 45:37-45

Publisher's note Springer Nature remains neutral with regard to jurisdictional claims in published maps and institutional affiliations.

\section{Affiliations}

\section{Zhi-Qiang Chen ${ }^{1} \cdot$ Hong Nguyen Thi Hai ${ }^{1,2} \cdot$ Andreas Helmersson $^{3} \cdot$ Mateusz Liziniewicz $^{3} \cdot$ Henrik R. Hallingbäck $^{1,4,5}$. Anders Fries ${ }^{1} \cdot$ Mats Berlin ${ }^{5} \cdot$ Harry X. Wu ${ }^{1,6,7}$}

1 Umeå Plant Science Centre, Department of Forest Genetics and Plant Physiology, Swedish University of Agricultural Sciences, Linnaeus väg 6, SE-901 83 Umeå, Sweden

2 Forest Science Institute of South Vietnam, 1 Pham Van Hai,Tan Binh District, Ho Chi Minh City, Vietnam

3 Skogforsk, Ekebo 2250, SE-268 90 Svalöv, Sweden
4 Department of Plant Biology, Uppsala BioCenter, Linnean Centre for Plant Biology, Swedish University of Agricultural Sciences, P.O. Box 7080, SE-750 07 Uppsala, Sweden

5 Uppsala Science Park, Skogforsk, SE-75183 Uppsala, Sweden

6 Beijing Advanced Innovation Centre for Tree Breeding by Molecular Design, Beijing Forestry University, Beijing, China

7 Black Mountain Laboratory, CSIRO National Collection Research Australia, Canberra, ACT 2601, Australia 